\title{
¿ES LA CÁRCEL EL CASTIGO MÁS ACORDE A NUESTROS TIEMPOS?
}

\author{
JUAN JOSÉ RICHTER* \\ Pontificia Universidad Católica de Chile
}

\begin{abstract}
RESUMEN: En virtud de un acercamiento a la teoría sociológica, a la luz de los postulados de Durkheim, Foucault y Weber, el presente artículos nos analiza las diversas estrategias punitivas que buscan reprimir y moralizar a los criminales, las cuales han variado en el tiempo atendiendo a la sensibilidad de cada sociedad. Sin duda, una de las políticas represivas más aplicadas es la cárcel, en torno a la cual el autor debate su justificación, intensiva utilización y la existencia de una clara tendencia mundial hacia el encarcelamiento, pese a sus falencias.
\end{abstract}

Palabras clave: Cárcel, eficacia, teoría sociológica, venganza, sensibilidad, violencia.

ABSTRACT: Under a rapprochement with the sociological theory, in the light of the tenets of Durkheim, Foucault and Weber, this article examines several punitive strategies that seek to suppress and moralize criminals, which have varied in time in response to the sensitivity of each society. Undoubtedly, one of the repressive policies more applied is the prison, around which the author questions its justification, intensive use and the existence of a clear global trend towards imprisonment, despite its shortcomings.

Key words: Prison, effectiveness, sociological theory, revenge, sensitivity, violence.

Al hablar de castigo en la actualidad, no se puede dejar de pensar en la cárcel, ya que esta ocupa un sitial primordial como sanción en las personas que cometen delitos penales. Un gran número de países presenta un crecimiento sostenido de personas recluidas entre los años 90 y la actualidad, en especial Latinoamérica -salvo Bolivia y Venezuela- y los países de tradición anglosajona -EE.UU., Inglaterra, Australia-. Se podría pensar que lo anterior se encuentra ligado a cambios demográficos. Sin embargo, observando la Prision population rate (tasa de reclusos por cada cien mil habitantes), se puede constatar que la cantidad de personas encarceladas ha aumentado por sobre el crecimiento poblacional.

Una paradoja que emerge desde este panorama es ¿por qué la cárcel ha logrado tal relevancia si muchos expertos llevan años criticando su eficacia, llegando algunos a plantear que es un verdadero fracaso? ${ }^{1}$. Es presumible que la dificultad de resolver esta pregunta esté ligada a su complejidad y no es el fin de este escrito enmendarla. Aún así, se intentará aportar reflexionando sobre una dimensión del castigo que muchas veces se diluye detrás de leyes y cifras, su dimensión simbólica.

\footnotetext{
* Sociólogo, Pontificia Universidad Católica de Chile.

${ }^{1}$ Foucault, Michel. Vigilar y Castigar. p. 160. <En línea>, Buenos Aires, Siglo XXI, 2002. [Citado 25 mayo 2009 ]. Disponible en World Wide Web <http://www.uruguaypiensa.org.uy/imgnoticias/592.pdf>.
} 


\section{TABLA 1}

Paises en que han aumentado las cantidades de población penal en las últimas dos décadas (Cantidad de reclusos por país, en paréntesis se presenta la tasa de reclusos por cada cien mil habitantes).

\begin{tabular}{lcccc}
\hline País & 1992 & 2001 & 2004 & 2007 \\
\hline Brasil & $114.377(74)$ & $233.859(133)$ & $336.358(183)$ & $422,590(220)$ \\
Chile & $20.989(155)$ & $34.717(225)$ & $38.064(238)$ & $45.843(276)$ \\
Argentina & $21.016(63)$ & $41.007(109)$ & $54.472(140)$ & - \\
Perú & $15.718(71)$ & $26.968(105)$ & $31.311(116)$ & $39.684(141)$ \\
El Salvador & $5.348(99)$ & $9.679(150)$ & $12,113(179)$ & - \\
México & $85.712(98)$ & $165.678(164)$ & $193.889(183)$ & $212.841(193)$ \\
EE.UU. & $1.295 .150(505)$ & $1.961 .247(685)$ & $2.135 .335(723)$ & - \\
Inglaterra y Gales & $44.719(88)$ & $66.301(127)$ & $74.657(141)$ & $80.216(148)$ \\
España & $35.246(90)$ & $46.962(117)$ & $59.224(138)$ & - \\
Holanda & $7.397(49)$ & $15.246(95)$ & $20.075(123)$ & $18.103(110)$ \\
Japón & $45.082(36)$ & $65.508(51)$ & $76.413(60)$ & - \\
Australia & $15.559(89)$ & $22.458(116)$ & $24.171(120)$ & - \\
Nueva Zelandia & $4.217(119)$ & $5.887(152)$ & $6.556(160)$ & $7.059(188)$ \\
\hline
\end{tabular}

Fuente: Elaboración propia a partir de la World Prison Brief, a la fecha en http://www.kcl.ac.uk/depsta/law/research/icps/ worldbrief/

\section{CONCEPTOS SOCIOLÓGICOS}

Para poder aprehender el simbolismo que está detrás del castigo es necesario revisar los principales conceptos que ha desarrollado la sociología sobre este. En "Castigo y Sociedad Moderna”, David Garland lleva a cabo una certera revisión de lo que la teoría sociológica ha pensado sobre el castigo. A continuación se discutirán los conceptos más relevantes.

\section{A. PaSión Y EMOCIÓN IRRACIONAL COMO SUSTENTO DE LA PENA (DURKHEIM)}

Un punto de partida en la comprensión del simbolismo del castigo es la importancia que la sociedad en su conjunto le confiere. Un análisis muy detallado de esta valoración social se encuentra en la obra de Emile Durkheim para quien, según Garland, el castigo es considerado "como una institución social que es, en primera y última instancias, un asunto de moralidad y solidaridad sociales" 2 . En la moralidad se puede comprender la esencia del castigo, que más que la racionalidad es una reacción emotiva, principalmente irreflexiva que responde a la profanación de aquello que la sociedad tiene en más alta estima, de lo sagrado. Para Durkheim el concepto de lo sacro trasciende la religión, ya que en la sociedad seculari-

\footnotetext{
${ }^{2}$ Garland, David. Castigo y Sociedad Moderna: un estudio de teoría social. Madrid: Siglo Veintiuno Editores, 1999 , p. 45.
} 
zada siguen existiendo valoraciones de este carácter, sentimientos sociales profundamente arraigados que pueden provocar un gran repudio si son transgredidos, en tanto "la cosa sagrada es, por excelencia, aquella que el profano no debe, no puede tocar impunemente"3.

La importancia, o carácter sagrado, que una sociedad le atribuye a ciertos valores o conceptos dialoga íntimamente con el castigo que se le confiere a quien los ultraja. Así es como en la edad de los reyes los castigos más espectaculares eran aplicados a quienes atentaban contra la figura real o su autoridad, mientras que en sociedades democráticas se tiende a sancionar con mayor crudeza a quienes atentan contra la vida de las personas. De hecho, no es solo la figura del rey en la edad media, o el valor de la vida en la actualidad lo que se intenta preservar con el castigo, sino también el frágil orden social que se sostiene en estos valores fundantes. Específicamente, lo que se busca defender es la autoridad que emana de las normas que preservan dichos valores, y que al mismo tiempo mantiene en orden las tensiones generadas por intereses particulares, permitiendo la cohesión necesaria para que una sociedad, o en términos modernos un Estado, permanezca en el tiempo: "una violación moral desmoraliza (...) la ley que ha sido violada debe atestiguar de alguna manera que, pese a las apariencias, sigue estando en pie, que no ha perdido su fuerza o autoridad pese al acto que la repudió" ".

La penalidad se manifiesta de manera depurada a la luz de Durkheim, sin la neblina de las corrientes rehabilitadoras o disciplinarias posteriores. El castigo se ve al desnudo como la comunicación de un sentimiento profundo y en ocasiones visceral, que en su versión más ideal preserva las conductas deseadas socialmente, pero que al mismo tiempo tiene un carácter vengativo. Es el deseo de venganza, el agravio moral el que impulsa la pena, su motivación emana del interior más que del exterior y es el Estado el que solo asume el control del proceso graduando la pasión espontánea, pero no controla su origen 5 .

El deseo de venganza se puede manifestar de dos maneras a través del castigo. Por un lado, puede ser individual, es decir, emergiendo del o los afrentados, cuando se refiere a normas valoradas socialmente que en su transgresión afectan de manera focalizada a uno o más individuos sin poner en riesgo la autoridad de las normas. En este caso los individuos son quienes quieren cobrar venganza por el agravio que se les ha cometido, pero entregan su derecho al Estado, que posee el monopolio de la violencia en sociedades modernas. Así, la sociedad aprueba la venganza en tanto se actúa legalmente y los afrentados son representados por diversos organismos oficiales en la comunicación de esta. Por otro, puede ser que la venganza emerja de la sociedad en su conjunto, cuando un crimen atenta contra la autoridad misma de las normas socialmente vigentes o cuestiona los valores más profundos. En ese sentido, la sociedad en su conjunto no solo aprueba el acto vengativo, sino que también es la que lo exige, comunicando dicha sensibilidad también a través de los organismos oficiales. En este último caso es cuando más peligra el orden social si el criminal no es sancionado, ya que la autoridad misma que permite dicho orden se ve cuestionada por el crimen.

\footnotetext{
${ }^{3}$ Durkheim, Emile. Las Formas elementales de la vida religiosa. Madrid: Ediciones Akal universitaria, 1992 , p. 43.

${ }^{4}$ Durkheim, Emile. "La educación moral”. En: Garland, David. Castigo y Sociedad Moderna: un estudio de teoría social. Madrid: Siglo Veintiuno Editores, 1999, p. 62

${ }^{5}$ Garland, David, op. cit. (n. 2), p. 82.
} 
Desde la concepción comunicativa ya mencionada, el lenguaje práctico del castigo, a decir las sanciones, dependerán de la sensibilidad de cada sociedad. En aquellas donde es difícil afectar la sensibilidad individual posiblemente sea necesario traducir la culpa a formas violentas. En cambio, en sociedades modernas que tienen sensibilidades más refinadas, los sentimientos no necesitan comunicarse a través de castigos físicos brutales ${ }^{6}$. No se pueden obviar las limitantes de la visión durkheimiana sobre la relación entre sensibilidad social y castigo, donde no se integra claramente el rol que juega el poder, ya que en algunas sociedades no siempre las normas emergen de la voluntad popular -descrita en términos ideales por Rousseau y base del actual sistema democrático representativo-, si no que son la cristalización de los grupos dominantes o de los dictadores, quienes definen los parámetros de lo correcto y de lo que se debe desaprobar oficialmente. Asimismo, el poder se manifiesta en tanto la violencia no deba ser aplicada, es decir, su recurso último es el uso de la violencia, por esto el castigo se debe aplicar con más frecuencia cuando la autoridad es más débil y por lo mismo tiene un efecto menor ${ }^{7}$.

\section{B. EL SURGIMIENTO DEL DELINCUENTE}

La herramienta que se ha vuelto más popular en la comunicación de los sentimientos sociales mencionados por Durkheim es, sin duda la prisión, que permite castigar sin violencia a los criminales respondiendo a la sensibilidad refinada de las sociedades modernas. Antes de la existencia de las cárceles no se tenía gran conocimiento sobre los criminales, por lo que no era tan claro que tuviesen características similares entre ellos, ni menos que compartieran un ethos en común, más allá de la maldad o ignorancia que se les atribuía. La prisión permitió conocer cuáles eran sus comportamientos y rasgos físicos, sus costumbres y forma de hablar, surgiendo la imagen del "presidiario", personaje que se hizo presente en la literatura y la pintura decimonónica.

Michel Foucault en Vigilar y Castigar radicaliza esta idea. En su famosa obra plantea que la prisión no solo permitió conocer más claramente a quienes cometían crímenes, sino que fabricó la figura del delincuente. Esto se observa principalmente en dos sentidos: creando las condiciones propias para la reincidencia, como la estigmatización social y la desmoralización; y en un sentido epistemológico, produciendo la categoría de criminal individual, objeto de control y de estudio ${ }^{8}$. En palabras de Foucault:

Si bien es cierto que la prisión sanciona la delincuencia, esta, en cuanto a lo esencial, se fabrica en y por un encarcelamiento que la prisión, a fin de cuentas, prolonga a su vez. (...) El delincuente es un producto de institución (...) En una palabra, el archipiélago carcelario asegura, en las profundidades del cuerpo social, la formación de la delincuencia a partir de los ilegalismos leves, la recuperación de estos por aquella y el establecimiento de una criminalidad especificada?

\footnotetext{
${ }^{6}$ Ibid., p. 63.

7 Ibid., p. 81.

${ }^{8}$ Ibid. pp. 179-180.

${ }^{9}$ Foucault, Michel, op. cit. (n. 1), p. 184.
} 
Para la sociedad en su conjunto es útil poder definir el perfil del delincuente, en tanto les permite anticiparse al crimen, sin embargo, a pesar de los avances de la criminología muchas veces se cae en la estigmatización. En este sentido, se puede caer en tildar a una persona como criminal por sus rasgos físicos, por su forma de hablar o de vestirse, sin que necesariamente ella haya cometido un delito. Se pueden limitar así las expectativas sociales de ciertos individuos, aumentando sus probabilidades de convertirse en lo que parecen ser. Otra dificultad de la estigmatización es la autocomprensión del delincuente como tal, lo que hace peligrar su reinserción a la sociedad, así como también a su núcleo cercano, creando más delincuencia en vez de controlarla.

La autocomprensión del criminal como alguien al margen de la ley no es propiamente un fenómeno posterior a las cárceles modernas. Si bien existía, nunca antes había sido posible en la magnitud que la prisión lo permite. Esta, en cuanto institución total ${ }^{10}$, al clausurar las relaciones que se dan en su interior genera las condiciones para que emerja no solo el presidiario, sino una suerte de subcultura carcelaria, con valoraciones, costumbres y hasta un lenguaje propio -conocido en Chile como "coa"-. En este sentido, Garland plantea que el recluso se aferra de la cultura interior alternativa que emerge en la prisión para mantener cierta autonomía y respeto a sí mismo, evitando ser esclavo del sistema oficial. De hecho, es en aquellas prisiones donde los reclusos pueden identificarse con una subcultura carcelaria donde ocurre con mayor frecuencia la resistencia a la autoridad oficial ${ }^{11}$. Esta cultura interior alternativa opera aumentando el estigma y la identificación criminal del ex recluso, al hacer referencia a conductas que pueden ser fuente de discriminación por parte de la sociedad, como lo son la violencia y el engaño.

\section{Profesionalización del CASTigo (Burocracia Carcelaria)}

La administración de las cárceles y los procesos del sistema penal en general -es decir el juicio como la sanción- han seguido las tendencias expansivas de racionalización que emergen en diversos ámbitos de la sociedad. Desde la tradición de Max Weber se puede comprender cómo estas tendencias racionalizadoras han afectado los procedimientos judiciales, burocratizándolos, vale decir, definiendo pormenorizadamente su funcionamiento para que opere de manera neutral y objetiva. La burocracia se inspira en el método científico, donde lo importante es la rigurosidad y meticulosidad con que se llevan a cabo los procedimientos. En este sentido, Weber afirma que dichas organizaciones se vuelven deliberadamente "deshumanizadas" y, en tanto que se aproximan a este ideal, logran "eliminar del campo social el amor, el odio y todos [...] los elementos irracionales y emocionales"12. Razón por la cual en el proceso penal que llevan a cabo las entidades oficiales se busca neutralizar la afectividad, dejándola para la audiencia o la opinión pública. En

\footnotetext{
10 Sobre el concepto de institución total de Erwin Goffman vea: LOZANO, Blanca. "En el aniversario de Erwin Goffman (1922-1982)", en Revista española de investigaciones sociológicas. <En línea>, ISSN 0210-5233, Nº102, 2003 , pp. 47-61. [Citado 25 Mayo 2009] Disponible en World Wide Web: <http://dialnet.unirioja.es/servlet/ fichero_articulo? codigo $=767062$ \&orden $=81291>$

11 GARLAND, David. op. cit. (n. 2), p. 205.

12 Gerth y Mills (comps.). From Max Weber, p. 214. En: Garland, David. op. cit. (n. 2), p. 216.
} 
efecto, los profesionales del derecho penal no pueden operar a partir de la emotividad o las pasiones que puedan generar un determinado crimen, sino que deben abocarse a los procedimientos detalladamente definidos, solo así puede llevarse a cabo de manera correcta el proceso y, por ende, lograr que sea justo en un sentido oficial, reconocido por todos. De esta manera se entiende lo que planteaba Durkheim sobre la graduación que el Estado hace, a través de sus instituciones, de la pasión social generada por un delito. No solo el juicio se vuelve más técnico, sino también el castigo mismo, lo que burocratiza no solo el proceso, igualmente el funcionamiento de la prisión, incrementándose el rol de los expertos y su diagnóstico técnico. Las ciencias sociales, en esta línea, han tomado un rol preponderante en el tratamiento de los reclusos, complementándose la figura del "carcelero" que cuida al reo con la del "cientista social" quien lo provee de un servicio, de un tratamiento. Servicio que ya no es solo moral, ni depende de la buena voluntad de un sacerdote o una religiosa, es una asistencia que la misma prisión debe proveer además del castigo y más aún como parte de la condena.

Pareciera que la profesionalización del castigo supera sus pasiones subyacentes, pero esto no es más que una ilusión. Según Garland:

"El resentimiento, la indignación, el odio, al igual que la misericordia, la justicia y el perdón, siguen formando parte de estas medidas racionales, aunque de manera callada, sublimada, disfrazada de preocupación utilitaria por la disciplina institucional y la administración individual, de modo que incluso las acciones punitivas más transparentes suelen representarse en términos instrumentales "positivos"13.

\section{TRANSFORMACIONES DEL CASTIGO EN LA SOCIEDAD MODERNA}

Luego de haber presentado algunas características fundantes del castigo en la sociedad moderna, como son su motivación irracional, la figura del delincuente y la profesionalización de los procesos punitivos, es momento de revisar la transformación histórica que sustentan estos fenómenos descritos teóricamente y cuáles son sus implicancias en la comprensión del castigo en la actualidad.

\section{A. Del CASTigo público al PRIVAdo}

Según John Pratt, en su obra "Castigo y Civilización", la última ejecución pública en Inglaterra fue la de Michael Barret en 1868. Antes de dicho momento la muerte de un condenado era una festividad popular como cualquier otra, la multitud ve las ejecuciones del mismo modo que cualquier otra exhibición para la que no hay que pagar. Creo que lo ven como si fuera un combate organizado o cualquier otra exhibición de naturaleza similar [...] [la multitud] parece divertirse y disfrutar del acontecimiento que se viene a ver ${ }^{14}$.

\footnotetext{
13 Garland, David. op. cit. (n. 2), p. 222.

${ }^{14}$ Report from the Select Committee, 1856, p. 878, en: PRATT, John. Castigo y Civilización: una lectura sobre las prisiones y los regimenes carcelario, Barcelona, España: Gedisa 2006, p. 43.
} 
En las puertas del siglo XX, se comenzó a discutir a nivel mundial sobre el carácter carnavalesco que la multitud le daba a las condenas de los criminales, pero más que poner en tela de juicio la ejecución del criminal, lo que causaba molestia era el lugar de la ejecución y lo macabro que resultaba que la gente lo disfrutara. No era concebible que en una sociedad civilizada siguiesen existiendo este tipo de espectáculos donde se humillaba públicamente a un criminal, de hecho, en Inglaterra el mismo año que murió Barret se abolieron las ejecuciones públicas, no hubo conmoción, no hubo barreras y, sobre todo, no hubo ninguna multitud encarnizada de ladrones y prostitutas esperando ver morir al hombre (...) Ni siquiera había un policía, las ventanas frente a la cárcel estaban todas vacías (...) Ahora la muerte en la horca significa una ejecución silenciosa, terrible, donde la media docena o docena de espectadores tienen el deber doloroso de permanecer en su lugar hasta que el hombre es colgado hasta morir ${ }^{15}$.

Pero la pena de muerte siguió siendo fuertemente apoyada - "una propuesta de abolición de la pena de muerte fue derrotada en la Cámara de los Comunes por 127 votos contra 23 "I6-, dando paso a una nueva etapa en la aplicación del castigo, donde dejó de ser visto como un espectáculo público, y quedó abocado a los muros de la prisión. Ya no se buscaba hacer sufrir al criminal, sino simplemente que muriera, insertándose criterios modernizadores en el proceso que buscaban maximizar su eficiencia. La aplicación burocrática de la pena de muerte buscaba expresar el menor dolor y drama, en contraposición al carácter festivo de antaño ${ }^{17}$.

En distintos países se introdujeron nuevos métodos para terminar con la vida de los convictos, en Estados Unidos se comenzó a utilizar la silla eléctrica en 1889, en la Canadá de posguerra se consideró utilizar la inyección letal y la silla eléctrica en vez de la horca. En Inglaterra se simplificaron los rituales que dramatizaban las ejecuciones en 1901 y en 1925 se limitó la información acerca de la ejecución solo a un aviso que publicaba la prisión, sin cobertura mediática ${ }^{18}$.

Entre 1960 y 1970 surgieron visiones de avanzada en relación al castigo, con una sensibilidad mucho más desarrollada que la de tiempos pasados, surgiendo "la visión del delincuente como víctima involuntaria de la sociedad en vez de como un actor moral coherente, haciendo moralmente inaceptables sanciones punitivas como la pena de muerte" ${ }^{19}$. En estas reflexiones la sociedad se autoobserva como responsable en cierta medida del criminal, lo que se remonta a ciertas tradiciones ilustradas -como "el buen salvaje" rousseauniano- que plantean a la civilización como corrompedora de los individuos. Tras estas sensibilidades hay una nueva concepción sobre el Estado moderno y democrático, el que ya no se ve forzado a ejercer su autoridad desde una aplicación represiva de la ley. Se debe aclarar que estas reflexiones surgían en grupos reducidos de la sociedad, ya que los sentimientos del público en general seguían apoyando la pena de muerte.

Surge así una tensión entre la opinión pública y el Estado.

\footnotetext{
15 The Times, 9 de septiembre de 1868, p. 5. En: PRATT, John. op. cit. (n. 14), pp. 43-44.

16 PRATT, John. op. cit. (n. 14), p. 38.

17 Ibid., p. 47.

18 Ibid., pp. 48 y 49.

${ }^{19}$ Ibid., p. 53.
} 
"La opinión pública, con su sentido común en vez de con un conocimiento razonado y racional, había sido separada del proceso de legislación y castigo. Al menos con relación a la pena de muerte, el Estado y sus funcionarios, en la mayoría de los países del mundo civilizado, decidirían tales asuntos y estarían dispuestos a avanzar más allá de la opinión pública de acuerdo a su propio criterio" ${ }^{20}$.

Pero la sensibilidad no alcanzaría a generar mayores cambios, cuestionando la linealidad del proceso civilizador, ya que en los años siguientes la prisión dejó de ser vista como la opción penal de último recurso, creciendo considerablemente la población carcelaria durante la década de 1970. En Inglaterra, por ejemplo, aumentó de 39.280 a 43.109 entre 1975 y 1980, y en Estados Unidos en 1980, la población de hombres adultos encarcelados llegó $304.256^{21}$.

Las cárceles, cada vez más llenas comenzaron a considerarse como un lugar de violencia y desorden, perdiéndose el optimismo profesionalizante de las décadas anteriores; los esfuerzos oficialistas de reafirmar la función contenedora de la prisión produjo más caos en su interior. Las autoridades comenzaron a temerle a los reclusos, quienes fortalecían su autoestima y sentido de solidaridad a partir de las nuevas iniciativas y clasificaciones de seguridad aplicadas en las cárceles ${ }^{22}$. La preocupación general no era sobre la cantidad de personas que eran encarceladas, sino por la incapacidad cada vez mayor de las instituciones penitenciarias y, por ende, del Estado, de controlar la delincuencia y el orden al interior de los centros de reclusión ${ }^{23}$.

Este nuevo panorama llevó a una reconfiguración de los actores en discusión y de la concepción social sobre la prisión. El creciente número de personas encarceladas se entiende en esta nueva concepción del castigo, donde la prisión se empieza a ver como eficaz, no en tanto corrige la conducta desviada del transgresor a través del tratamiento profesional que -como dijimos- había fracasado, sino en tanto mantiene "a sus poblaciones depredadoras alejadas del resto de la sociedad" 24 . Así, las autoridades comienzan a sentirse orgullosas por la magnitud creciente de delincuentes recluidos, cegándose frente a la real ineficiencia del método desde el punto de vista de la ejecución de sus objetivos constitutivos; "no me preocupa tanto como a otros el tamaño de la población carcelaria. Debiera estar determinado por la decisión de los tribunales de enviar gente a la prisión” 25 .

En el ocaso del siglo XX, pareciera que la tensión Estado-opinión pública se ha inclinado hacia el lado de la última, preponderando la sensibilidad de la gran mayoría por sobre las visiones minoritarias que critican el castigo desmesurado, como en los tiempos del carnaval mortuorio de la ejecución pública. En palabras de Pratt "en vez de que el Estado central eduque a la gente y la conduzca por un camino racional y razonado de desarrollo, es como si se invirtiera la situación, con el eje del poder penal cada vez más lejos del racionalismo burocrático dominante del Estado orientado hacia la punitividad

${ }^{20}$ Ibid., p. 57.

${ }^{21}$ Ibid., p. 223.

${ }^{22}$ Ibid., p. 218.

${ }^{23}$ Ibid., p. 229.

24 Ibid., p. 251.

25 Secretario del Interior de Inglaterra, The Guardian, 13 de mayo de 1993, p. 3. En: PrATT, John, op. cit. (n. 14), p. 250. 
emotiva de los ciudadanos" 26 . La deslegitimación de las autoridades causada por la ineficiencia de la prisión moderna y por el aumento de la delincuencia, ha generado un panorama insostenible donde el castigo por excelencia parece ser la reclusión.

Se potencia así un peligroso espiral donde el temor atribuido a la delincuencia fomenta iniciativas legales que en vez de disminuirla fortalecen la identificación con el ambiente delictual. Se estigmatiza a quien ha infringido la ley, limitando sus posibilidades de cambio al encasillarle en una condición que parece ser de por vida, como si no pudiese hacer otra cosa que seguir delinquiendo. El mismo temor a la delincuencia puede fomentar la reincidencia y, lo que es peor, puede generar delincuentes más peligrosos, ya que no discrimina entre grados de peligrosidad, ni circunstancias psicológicas o sociales, nombrando a personas muy diversas con la misma etiqueta, como "delincuente", identificándolos con una subcultura de violencia e ilegalidad que al parecer no presenta vías de superación. Un ejemplo paradigmático de la estigmatización es la Ley Megan, promulgada en los noventa en Estados Unidos, la que permite registrar de por vida a las personas que han cometido un delito sexual contra menores, para que los habitantes de los distintos estados sepan si alguno de estos delincuentes vive cerca de ellos. Sobre la promulgación de esta ley el presidente Clinton dijo: "respetamos los derechos de la gente, pero hoy, en Estados Unidos, no hay derecho mayor que el de un padre a criar a su hijo con seguridad y amor. (...) Estados Unidos está alerta: si usted se atreve a atacar a nuestros niños, la ley le seguirá a donde vaya, de Estado en Estado, de pueblo en pueblo" 27.

\section{B. Evolución del CASTigo EN Chile}

La historia del castigo en nuestro país tiene características particulares que son dignas de revisar, algunas de ellas siguen las influencias anglosajonas mencionadas más arriba. En las décadas que siguieron a la independencia se sintieron los costos económicos de esta empresa, plasmado en los miles de indigentes de las provincias del sur que migraron a las áreas urbanas sumándose a los sectores populares que, en vista de los mencionados descalabros económicos, se vieron propensos a caer en la delincuencia. Bajo este panorama, las estrategias punitivas buscaban reprimir y moralizar a los criminales, "como era claro que para remediar la criminalidad no bastaban solo las medidas punitivas, se hicieron renovados esfuerzos para moralizar a la población (...) Fundamentalmente a través de la educación (...) creándose para tal efecto numerosas escuelas en zonas rurales y urbanas. De este modo, junto con las medidas de terror (muerte, azotes, trabajos forzados), que no se extirparon por completo, lentamente apareció en escena la necesidad de regenerar la naturaleza delictiva" 28 .

Las formas del castigo en esta primera época chilena fueron diversas, desde el uso de la violencia manifestado en la pena de muerte y los azotes, la privación de libertad en lugares como la Cárcel Pública de Santiago, el asilamiento en la isla Robinson Crusoe

\footnotetext{
26 PRATT, John. op. cit. (n. 14), p. 253.

27 Oficina del Secretario de Prensa, La Casa Blanca, 25 de julio de 1995. En: PratT, John, op. cit. (n. 14), p. 258.

${ }^{28}$ LEÓn, Marco Antonio. Encierro y Corrección: la configuración de un sistema de prisiones en Chile (1800-1911). Santiago, Chile: Universidad Central de Chile, Facultad de Ciencias Jurídicas y Sociales, 2003, p. 146.
} 
("más a tierra") o la colonia de Magallanes, hasta el Presidio Ambulante ideado por Diego Portales que buscaba hacer más eficiente los trabajos forzados. Este último comenzó a ser utilizado alrededor de 1836, donde grandes carros enrejados trasladaban a los presidiarios hacia las zonas de trabajo, principalmente reparación y construcción de caminos, sirviéndose de una suerte de celda donde los hombres dormían. Además de buscar facilitar el traslado de los presos hacia las zonas de trabajo, el presidio ambulante era un espectáculo para amedrentar a los ciudadanos a través de la humillación de los infractores.

Sólidas jaulas de fierro que se colocan de fijo sobre las carretas muy poco más grandes que las comunes, pero de construcción firme y segura (...) Cada jaula estaba dividida en tres secciones horizontales y en cada una de estas había capacidad para seis hombres, que debían permanecer tendidos porque no había espacio para sentarse. Los criminales están ligados de dos en dos por fuertes cadenas sujetas a un sólido anillo de fierro remachado en una pierna, a la altura del tobillo ${ }^{29}$.

Las corrientes civilizadoras también incidieron al cuestionar la utilización de las jaulas-carreta. Las malas condiciones de vida del presidio ambulante y la sociabilidad que se daba tras las rejas endurecía al simple ladrón, volviéndolo propenso a incurrir en el futuro en delitos más graves. De hecho, un gran número de condenados a este tipo de castigo eran padres de familia que habían cometido robos de animales y otras especies, en gran medida por la responsabilidad que tenían sobre sus hombros ${ }^{30}$. Esto, sumado a numerosas revueltas tanto de los presos como de los vigilantes, aceleró las discusiones sobre el castigo, buscándose nuevas formas de aplicación. El referente en esa época era Estados Unidos con el modelo de la cárcel de Auburn -en el estado de Nueva York- el que se puso en práctica con la construcción de la Penitenciaría de Santiago en 1843. Su funcionamiento era "reclusión solitaria en horas destinadas al sueño y al alimento, y reunión de los presos únicamente para la instrucción primaria o religiosa y para el aprendizaje de el oficio lucrativo a que cada uno manifieste más inclinaciones o aptitudes"31. Las primeras celdas de la Penitenciaría se habilitaron en 1847, trasladándose los condenados desde el presidio ambulante, pero sin respetar la idea original de mantener un reo por celda, instalándose cuatro en cada una de ellas ${ }^{32}$. Desde ahí se siguieron construyendo más celdas y según datos recopilados por León, de los 320 reclusos que había en 1847 , se llegó a 800 en $1911^{33}$.

De aquí en adelante la administración del castigo quedó abocada principalmente a la prisión, donde se buscaba mantener a los criminales aislados de la comunidad, mientras se los intentaba corregir desde el trabajo, la educación y la religión. Estas fueron las bases del castigo en Chile durante el siglo XX, el que no sufrió mayores transformaciones. A pesar de lo anterior, se debe considerar que en la primera mitad de siglo fueron llegando a Chile las discusiones y corrientes relacionadas con lo punitivo. Tendencias profesionaliza-

\footnotetext{
29 Barros Arana, Diego. Obras Completas: Historia de Santiago, p. 311. En: Ortiz, Édison. La Penitenciaría: "Otra" aproximación a la Modernidad Chilena Decimonónica. <En línea>, 1996, p. 3, [Citado 25 Mayo 2009]. Disponible en World Wide Web: < http://www.cidpa.org/txt/6artic02.pdf >.

${ }^{30}$ LEÓN, Marco Antonio. op. cit. (n. 28), p. 312.

31 Sesiones Cuerpos Legislativos (1853), Tomo XXXIII, 26 de Julio de 1843, p.169. En: OrTIZ, Édison. op. cit. (n. 29 ), p. 3.

32 LEÓN, Marco Antonio. op. cit. (n. 28), p. 435.

33 Ibid., p. 454.
} 
doras fomentaron la creación en 1929 de una Escuela para el personal de tropa de Gendarmería de Prisiones -el cuerpo de Gendarmería de Prisiones ya había sido creado en 1911-, buscando una mejor administración de la custodia. También se vieron avances en materia del tratamiento de los reclusos, expresado en la creación en 1930 del Servicio Social de Prisiones, entidad encargada de colaborar en la readaptación de los reclusos y de ayudar a sus familias, además de apoyar a las víctimas de delitos. Esta labor introdujo la utilización de diagnósticos con metodologías de la época tales como el uso de encuestas ${ }^{34}$.

En la segunda mitad del siglo, la custodia de las prisiones queda en manos de la institución que se conoce actualmente, Gendarmería de Chile, cuya ley orgánica vigente hasta nuestros días fue dictada en 1979, constituyéndola como institución de servicio público que depende del Ministerio de Justicia. La ley mencionada define como roles de la institución tanto la custodia, como la rehabilitación de los criminales, radicalizando la profesionalización que venía de la primera mitad del siglo.

\section{LA CÁRCEL, CASTIGO PRIMORDIAL EN EL CHILE ACTUAL}

El comienzo del siglo XXI trajo consigo numerosos cambios en la concepción del castigo en Chile. En primer lugar, se implementó el sistema de concesiones a privados para la construcción y administración de las cárceles, a pesar de que Gendarmería sigue teniendo bajo su cargo la custodia de los reclusos. Por otro lado, se disminuyó la edad en que una persona es responsable de un delito, con la Ley 20.084 de Responsabilidad Penal Adolescente, a través de la cual menores de hasta 16 años pueden ser sancionados con un máximo de 10 años de cárcel si cometen un delito. Todo esto incrementa la cantidad de personas que pueden ser privadas de libertad, a pesar que en relación a la concesión de cárceles, uno de los principales argumentos no es aumentar la cantidad de reclusos, sino mejorar las condiciones de hacinamiento en las que viven.

Junto con esto, se puede apreciar el menor número de condenas alternativas a la reclusión -remisión condicional de la pena, libertad vigilada del adulto, reclusión nocturnaque están cumpliendo infractores en Chile en relación al encarcelamiento, siendo 45.694 los adultos en el sistema semicerrado y 49.225 en el cerrado al 30 de abril del año en curso ${ }^{35}$.

En conclusión, la pregunta que se reitera es ¿por qué la prisión sigue siendo una forma tan utilizada de castigo en el sistema penal chileno? Una respuesta apresurada podría fundamentar este hecho en una suerte de tendencia mundial, ya que en numerosos países de todos

\footnotetext{
${ }^{34}$ Más información en: Correa, María José. "Demandas Penitenciarias: Discusión y Reforma de las cárceles de mujeres en Chile (1930-1950)", en Historia. <En línea>, Pontificia Universidad Católica de Chile, Volumen 38 N $^{\circ} 1,2005$. Disponible en World Wide Web: < http://www.scielo.cl/scielo.php?script=sci_arttext\&pid=S0717$71942005000100002 \& \operatorname{lng}=e s \& n r m=i s o$ >; y CANDINA, Azun. "Seguridad Ciudadana y Sociedad en Chile Contemporánea. Los delincuentes, las políticas y los sentidos de una sociedad”, en Revista de Estudios Históricos. <En línea>, Departamento de Ciencias Históricas, Facultad de Filosofía y Humanidades, Universidad de Chile, Volumen $2 \mathrm{~N}^{\circ} 1$, Agosto 2005. Disponible en World Wide Web: <http://www.estudioshistoricos.uchile.cl/CDA/est_hist_complex/ 0,1475,SCID\%253D15044\%2526ISID\%253D540\%2526PRT\%253D14999,00.html>

35 GENCHI, Estadísticas de Población Penal Atendida. <En línea> Sitio web oficial. [Citado 25 Mayo 2009] Disponible en World Wide Web: <www.gendarmeria.cl>
} 
los continentes se ven preferencias similares hacia el encarcelamiento. Pero también existen países que han reducido considerablemente la cantidad de personas presas como lo son Canadá, Alemania, en contraposición con los que la han mantenido, así India. Además existen particularidades propias de cada Estado que podrían generar mayores niveles de encarcelamiento, poca integración de etnias migrantes o una visión de la prisión con fines económicos. En este sentido, se vuelve fundamental cuestionar la magnitud de la población carcelaria en Chile como un fenómeno particular, buscando cuáles son aquellos condicionantes propios de nuestra sociedad y de nuestra cultura que subyacen a este hecho.

Para finalizar el presente escrito, más que dar una clara respuesta a la pregunta que nos convoca, se intentarán elucubrar algunas tesis a partir de lo expuesto anteriormente, más heurísticas que fundamentadas empíricamente, con el fin de guiar líneas investigativas que en un futuro puedan resolver dicha interrogante.

En primer lugar, después de la vuelta a la democracia, los medios de comunicación recuperaron completamente la libertad de prensa que, junto con un tremendo desarrollo tecnológico, les ha permitido reflejar en mayor magnitud y, quizás, con más claridad la opinión pública. En relación a la delincuencia, lo reflejado por los medios es una creciente sensación de inseguridad de los ciudadanos, quienes por su temor tienden a consumir más programas y noticias policiales. Por la inseguridad, las personas han exigido mayor severidad a las autoridades para sancionar a los infractores, lo que ha llevado a que se condene a presidio a más personas de las que pueden ser atendidas por las cárceles. Ejemplo de esto es la oleada de violencia que se ha dado en la cárcel de Colina II, donde hace un mes se trasladaron reclusos peligrosos desde la cárcel de San Miguel a quienes se les atribuyen conflictos de envergadura, como por ejemplo, un incendio que se produjo en una de las piezas y que dejó 10 muertos, a fines de abril del presente año. Este traslado se debió a que la cárcel concesionada Santiago I estaba sobrepoblada y, a diferencia de las cárceles estatales, el Estado debe pagarle al concesionario diariamente si es que los tribunales envían a más personas de las que están estipuladas en el contrato.

En segundo lugar, esta exigencia popular de "mano dura" a los criminales, que recuerda los postulados de Durkheim mencionados en este escrito, tiene el potencial de ser utilizado políticamente. Este uso se aprecia en campañas electorales y, más aún, durante periodos de gobierno, con el fin de facilitar la cohesión social que otras medidas gubernamentales no han podido lograr, como las viviendas sociales que han generado exclusión y estigmatización en la zona sur de Santiago o la deficiente calidad de la educación municipal que limita las oportunidades de ascender socialmente de miles de niños.

La paradoja que queda sin resolverse, alude a la racionalidad del castigo en la sociedad actual, donde a pesar de reducirse el uso de la violencia y burocratizarse los procedimientos de su aplicación, la prisión no ha logrado ser superada por otras formas punitivas que logren reformar efectivamente a los criminales o que por lo menos, les faciliten las oportunidades que la sociedad no les ha dado. Se podría decir que los avances tecnológicos han logrado mejorar la vigilancia y el control de los individuos, pero su rehabilitación ha quedado en deuda, como si las reflexiones sociológicas (de Durkheim, Foucault y Weber) más que iluminar a la sociedad actual, cambiando el curso de las cosas, han sido una premonición concretada. 


\section{REFERENCIAS BIBLIOGRÁFICAS}

Barros Arana, Diego. Obras Completas: Historia de Santiago, p. 311. En: Ortiz, Édison. La Penitenciaría: "Otra" aproximación a la Modernidad Chilena Decimonónica. <En línea>, 1996, p. 3, [Citado 25 Mayo 2009]. Disponible en World Wide Web: < http://www.cidpa.org/txt/6artic02.pdf >.

CANDina, Azun. "Seguridad Ciudadana y Sociedad en Chile Contemporánea. Los delincuentes, las políticas y los sentidos de una sociedad", en Revista de Estudios Históricos. <En línea>, Departamento de Ciencias Históricas, Facultad de Filosofía y Humanidades, Universidad de Chile, Volumen $2 \mathrm{~N}^{\circ}$ 1, agosto 2005. Disponible en World Wide Web: http://www.estudioshistoricos.uchile.cl/CDA/est_hist_complex/ 0,1475,SCID\%253D15044\%2526ISID\%253D540\%2526PRT\%253D14999,00.html

Correa, María José. "Demandas Penitenciarias: Discusión y Reforma de las cárceles de mujeres en Chile (1930-1950)", en Historia. <En línea>, Pontificia Universidad Católica de Chile, Volumen $38 \mathrm{~N}^{\circ} 1$, 2005. Disponible en World Wide Web: < http://www.scielo.cl/scielo.php?script=sci_arttext\&pid= S0717-71942005000100002\&lng=es\&nrm $=$ iso >

DurKheIM, Emile. "La educación moral". En: GARLAnd, David. Castigo y Sociedad Moderna: un estudio de teoría social. Madrid, Siglo Veintiuno Editores, 1999.

DurKheIM, Emile. Las Formas elementales de la vida religiosa. Madrid, Ediciones Akal universitaria, 1992.

Foucault, Michel. Vigilar y Castigar. p. 160. <En línea>, Buenos Aires, Siglo XXI, 2002.

Garland, David. Castigo y Sociedad Moderna: un estudio de teoría social. Madrid, Siglo Veintiuno Editores, 1999.

GENCHI, Estadísticas de Población Penal Atendida. <En línea> Sitio web oficial. [Citado 25 Mayo 2009] Disponible en World Wide Web: <www.gendarmeria.cl>

Gerth y Mills (comps.), From Max Weber. En: Garland, David. Castigo y Sociedad Moderna: un estudio de teoría social. Madrid, Siglo Veintiuno Editores, 1999.

LEÓn, Marco Antonio. Encierro y Corrección: la configuración de un sistema de prisiones en Chile (1800-1911). Santiago, Chile, Universidad Central de Chile, Facultad de Ciencias Jurídicas y Sociales, 2003.

LOZANO, Blanca. "En el aniversario de Erwin Goffman (1922-1982)", en Revista española de investigaciones sociológicas. <En línea>, ISSN 0210-5233, Nº102, 2003, pp. 47-61. [Citado 25 Mayo 2009] Disponible en World Wide Web: <http://dialnet.unirioja.es/servlet/fichero_articulo?codigo=767062 \&orden $=81291>$

PRATT, John. Castigo y Civilización: una lectura sobre las prisiones y los regimenes carcelarios, Barcelona, España, Gedisa 2006. 
